\title{
1 Examining the cost of delivering routine immunization in Honduras
}

2 Cara Bess Janusz $^{\mathrm{a} *}$, Carlos Castañeda-Orjuela ${ }^{\mathrm{b}}$, Ida Molina Berenice ${ }^{\mathrm{c}}$,

3 Ana Gabriela Felix Garcia ${ }^{\mathrm{a}}$, Lourdes Mendoza ${ }^{\mathrm{c}}$, Iris Yolanda Díaz ${ }^{\mathrm{c}}$, Stephen C. Resch $^{\mathrm{d}}$

4 a. Comprehensive family immunization unit, Pan American Health Organization, Washington, DC,

$5 \quad$ USA

6 b. Epidemiology and Public Health Evaluation Group. Universidad Nacional de Colombia, Bogota,

$7 \quad$ Colombia

8 c. Programa Ampliado de Inmunizaciones, Secretaría de Salud, Tegucigalpa, Honduras

9 d. Center for Decision Science, Harvard University, Boston, MA, USA

10

$11 *$ Corresponding author: Pan American Health Organization, 525 23rd Street NW, Washington, DC,

12 USA; Tel.: 202-974-3744.

13 Email address: januszc@paho.org;

14

(c) 2015. This manuscript version is made available under the Elsevier user license

http://www.elsevier.com/open-access/userlicense/1.0/ 
Background: Many countries have introduced new vaccines and expanded their immunization programs

24 to protect additional risk groups, thus raising the cost of routine immunization delivery. Honduras

25 recently adopted two new vaccines, and the country continues to broaden the reach of its program to

26 adolescents and adults. In this article, we estimate and examine the economic cost of the Honduran

27 routine immunization program for the year 2011.

28 Methods: The data were gathered from a probability sample of 71 health facilities delivering routine

29 immunization, as well as 8 regional and 1 central office of the national immunization program. Data were

30 collected on vaccinations delivered, staff time dedicated to the program, cold chain equipment and

31 upkeep, vehicle use, infrastructure, and other recurrent and capital costs at each health facility and

32 administrative office. Annualized economic costs were estimated from a modified societal perspective

33 and reported in 2011 US dollars.

34 Results: With the addition of rotavirus and pneumococcal conjugate vaccines, the total cost for routine

35 immunization delivery in Honduras for 2011 was US\$ 32.5 million. Vaccines and related supplies

36 accounted for $23 \%$ of the costs. Labor, cold chain, and vehicles represented $54 \%, 4 \%$, and $1 \%$,

37 respectively. At the facility level, the non-vaccine system costs per dose ranged widely, from US\$25.55

38 in facilities delivering fewer than 500 doses per year to US\$2.84 in facilities with volume exceeding

3910,000 doses per year. Cost per dose was higher in rural facilities despite somewhat lower wage rates for

40 health workers in these settings; this appears to be driven by lower demand for services per health worker

41 in sparsely populated areas, rather than increased cost of outreach.

42 Conclusions: These more-precise estimates of the operational costs to deliver routine immunizations

43 provide program managers with important information for mobilizing resources to help sustain the

44 program and for improving annual planning and budgeting as well as longer-term resource allocation

45 decisions.

47 Keywords:

48 Cost and Cost Analysis

49 Immunization

50 New vaccines 
51 Honduras

52 Latin America

53

54 


\section{Introduction}

Implementation of the Expanded Program on Immunization (EPI) in Latin America and the

57 Caribbean (LAC) has been broadly successful. Vaccination has been responsible for much of the

58 reduction in childhood mortality since the 1980s, and the LAC nations are on track to achieve Millennium

59 Development Goal 4 [1]. At the beginnings of these EPI programs, the routine delivery of childhood

60 vaccines, including Bacillus Calmette-Guérin (BCG), diphtheria-tetanus-pertussis (DTP), oral polio

61 (OPV), and measles (M), cost no more than US\$20 per fully immunized child. Today, the cost of

62 vaccines alone to complete the recommended schedules in most LAC countries far exceeds this cost [2].

63 There are newer, more expensive vaccines, including ones to prevent severe pneumonias, meningitis, and

64 diarrheas in children, as well as the human papilloma virus (HPV) that causes cervical cancer in women.

65 These new vaccines have demonstrated a favorable cost-effectiveness profile, but they often require a doubling or tripling of the budget envelope for their adoption into the routine program [3]. Additionally,

67 the health system costs associated with delivering vaccines are likely increasing due to the infrastructure investments required to incorporate new vaccines and a broadening of the program to include population groups beyond children [4].

Concern about growing costs has triggered an interest in strengthening capacity to track and analyze immunization costs, cost-effectiveness, budget impact, expenditures, and outcomes in order to

72 promote greater operational efficiency and sustainability. This trend has been especially true for countries

73 that are approaching a transition away from donor support. Honduras is one of six LAC countries that

74 receive new-vaccine subsidy support from Gavi, the Vaccine Alliance, which is a public-private

75 partnership that works to increase access to new vaccines in the poorest nations of the world. In 2011,

76 Gavi support subsidized $42 \%$ of the total cost of vaccines used in Honduras' national immunization

77 program [5]. But, like all other LAC countries supported by Gavi (except Haiti), Honduras is

78 "graduating" from Gavi eligibility due to economic growth and will soon face a higher, "graduated" cost 
for the newly adopted vaccines. For Honduras and its Gavi graduating peers, understanding the cost of routine immunization in the context of Gavi graduation is critical for planning and program sustainability.

In 2012-13, the Honduran Ministry of Health $(\mathrm{MoH})$ undertook a study to estimate the costs of the routine immunization program for the year 2011. The study was carried out in collaboration with PAHO's ProVac Initiative, which is a capacity-building effort to strengthen evidence-based decisionmaking concerning immunization policy [6]. This study was part of the Bill and Melinda Gates Foundation's EPI Costing and Financial Flows (EPIc) project, a study of the cost and financing of national immunization programs in six countries. Research teams in the EPIc network developed common methodological guidance and actively worked to harmonize their studies with this guidance [7]. This article reports the total and unit costs of routine immunization delivery in Honduras in 2011 and describes these costs in the context of programmatic performance and efficiency. A companion article in this special supplement to Vaccine explores financing for immunization services in Honduras in the same year [8].

\subsection{Routine immunization in Honduras}

In Honduras, the recommended schedule of childhood vaccines includes the traditional ones of BCG, Hepatitis B (HepB) infant dose, OPV, DTP/HepB/Hib, and measles-mumps-rubella (MMR), plus two recent additions, pneumococcal conjugate vaccine (PCV) and rotavirus vaccine (RV). The national immunization program also includes vaccines for other populations and diseases, including Tetanusdiphtheria (Td), yellow fever, influenza, and booster doses of DTP (Table 1). Additionally, there are assessments underway to evaluate introducing the HPV vaccine as soon as 2015 [9].

Among countries of the Americas in the same income grouping, Honduras' immunization program is considered a success story. With the help of sustained vaccination coverage above 90 percent in targeted risk groups, mainly children under 5 years old, Honduras has been free of polio since 1981 and measles since 1989 [10]. Recently, Gavi recognized Honduras for its notable achievement of reaching 
$98 \%$ coverage of the target population with the rotavirus vaccine within two years of the vaccine's

104 introduction into the routine schedule [11]. In 2011, Honduras reported that all children under the age of 2

105 years were fully vaccinated with all the recommended routine vaccines, with the exception of PCV13,

106 which had been newly introduced in the middle of that year. However, population coverage of childhood

107 vaccines in Honduras saw a slight downward trend after adjustments to the official denominator estimates

108 in more recent years. When using municipal-level denominators that do not account for migration,

109 coverage gaps appear to persist in vulnerable populations and difficult-to-access areas. Security problems

110 in the country have compounded the problem of suboptimal coverage in some districts [12]. Nonetheless,

111 the estimates available indicate coverage has been very high overall for many years [10].

The MoH delivers over 90 percent of all vaccinations in Honduras. The national immunization

113 program has its central administrative offices in the capital, Tegucigalpa. Regional offices in each of

114 Honduras' 20 sanitary regions oversee service delivery activities as well as organize and operate the

115 supply chain. At the municipal level, one health facility is designated as the "lead" facility for EPI, and

116 has some administrative role in managing immunization in the municipality's health facilities.

The vast majority of immunization service delivery occurs in three types of health facilities: (1)

118 hospitals; (2) CESAMO [Centro de Salud con Médico y Odontólogo] health centers, which are typically

119 found in more densely populated areas; and (3) CESAR [Centro de Salud Rural] health centers, which are

120 mostly found in rural areas. Immunization in hospitals is limited to newborn application of BGG and

121 hepatitis B doses (70 percent of all births occur in hospitals). Therefore, the bulk of immunization activity

122 occurs in CESAMO and CESAR health centers.

\section{Methods}

The methods for this study were guided by the "common approach" methodology for the EPIc multi- 
sampling protocol, scope and categorization of costs, preferred data sources and assumptions, and study

perspective. In Honduras, we retrospectively estimated the economic costs of the government-

129 administered routine immunization program for 2011, from a societal perspective that valued the

130 opportunity cost of all resources consumed in the delivery of immunization except patient time and

131 expenses (e.g., for transportation to clinics).

132 The routine immunization program is defined as the routine activities to deliver vaccines to the recommended target populations in Honduras. These routine activities include health facility-based vaccination, outreach activities, and the annual periodic intensification of routine immunization (PIRI) through mass social mobilization (which overlaps with Vaccination Week in the Americas) [13]. The annual total number of doses applied in the routine program includes those applied in-facility and out-of-

137 facility, but excludes doses applied to achieve a supplemental non-routine program goal, such as

138 vaccination of adult risk groups with the pneumococcal polysaccharide vaccine supply that Honduras 139 received as a donation in 2011. To facilitate comparison to other countries in the EPIc study, we also 140 present the portion of program cost for delivering immunization to children up to 1 year of age (see 141 Supplementary Appendix 1). All costs, other than for vaccines and syringes, were collected in the local 142 currency, lempiras, and converted to 2011 US dollars, with the official exchange rate of 18.8915 lempiras 143 to US\$ 1.00. Vaccines and syringe purchase records were already in US dollars. All capital costs were 144 annualized, with a three percent discount rate [14].

147 selected purposefully by the EPI to represent a range of settings in terms of the level of urbanization, 148 socioeconomic status, and geography. Two of the selected regions are geographically small, but very 149 populous metropolitan regions (Tegucigalpa and San Pedro Sula). The six other selected regions are 150 more characteristic of the country as a whole. Within the 8 regions, we gathered data from each regional 151 EPI office. In addition, using a multistage probabilistic design, we collected information from a sample of 
31 rural (CESAR) facilities and 40 urban health facilities (CESAMOs and hospitals) participating in the routine delivery of public sector vaccinations.

First, from each of the six non-metropolitan regions, three municipalities were selected without replacement and with probability proportional to the size of population under 1 year old. Then, in each municipality, the facility designated as the "lead" facility for EPI in the municipality was selected, as was

157 one non-lead CESAMO and one CESAR. The facilities were selected by simple random sampling within 158 these three strata. Most lead facilities were CESAMOs, but in three cases the lead facility was a hospital. 159 In some instances a municipality did not have a non-lead CESAMO or non-lead CESAR to select, and in 160 these cases, a facility of the other type was selected instead. The probability of selection for each facility 161 was calculated using a Monte Carlo simulation in which 10 million samples were drawn, and the 162 probability of selection equaled the fraction of samples containing the facility. After separating the doses 163 applied in the two metropolitan regions from the rest of the regions, characteristics of the selected 164 vaccination delivery sites are similar to other facilities in the sampling frame that were not selected and 165 other facilities outside of the frame, including the ratio of urban to rural sites and the mean number of 166 doses applied by health facility type (Table 2).

\subsection{Data collection}

Survey instruments were developed, tested, and then administered at all 71 health facilities and 169 eight regional offices selected in early 2013 (Supplementary Appendix 2). Data was entered in EpiInfo7 170 (U.S. Centers for Disease Control and Prevention, Atlanta, Georgia, USA) and exported to Microsoft 171 Excel 2010 (Microsoft Corporation, Redmond, Washington, USA). Structured interviews were conducted 172 with staff at the national immunization program offices in Tegucigalpa to capture costs at the central 173 level, and then this information was analyzed in the ProVac COSTVAC tool, also developed in Microsoft 174 Excel. COSTVAC was piloted previously in Colombia and Bolivia and is described elsewhere [15]. 

allowances, buildings, and other recurrent and capital costs. When resources were shared between the

177 routine immunization program and other health service delivery activities, only the proportions of each

178 shared resource reported as used by the immunization program were valued. Additionally, data on

179 vaccine, injection supplies, and other supplies and costs (including international freight and handling)

180 were collected at the central office. A bottom-up costing approach was used for these commodities, in 181 which the total number of vaccine doses delivered to patients was multiplied by the average price per 182 dose paid for vaccines in 2011, including transaction costs (insurance and fees), excluding transfers (e.g., 183 import duties), and accounting for reported vaccine-specific wastage rates. For the base case scenario, the unit price of Gavi-subsidized vaccines included both the portion of cost paid by Gavi and the portion paid by the Honduran government. The cost of syringes and supplies was similarly based on the number of vaccine doses delivered and unit prices, but, assuming 5\% wastage. Because the vaccine doses and associated vaccination supplies such as syringes, cotton, bandages, and rubber gloves are typically imported and have well-documented standard costs, we categorized this group of resource use as its own category, "Vaccines and Supplies." All other categories of resources required to deliver the immunization program are referred to as "system costs" (i.e., non-vaccine costs). These system-cost inputs (labor, equipment, vehicles, per diem and travel allowances, buildings, etc.) were apportioned across twelve 192 principal immunization program planning components used to develop annual and multiannual plans in 193 the Latin America and Caribbean region to understand the activity-based cost structure of the program 194 (Box 1).

\subsection{Data analysis}

After a modest correction factor was applied to account for differences between the sampled and

197 non-sampled municipalities, the inverse of the probabilities of selection was used as analytical weights in 198 the data analysis. Total costs were derived by extrapolating the weighted average system cost per dose 199 estimated for the sample, accounting for sample design, to all health facilities in Honduras. We excluded 
the administrative costs identified at the two metropolitan regional offices (Tegucigalpa and San Pedro

201 Sula), which were substantially higher than the costs in the other regions surveyed. We then averaged the

202 administrative cost per dose identified at all other regional offices and applied this average to non-

203 sampled regional offices in the country in order to estimate costs for this level. These extrapolated cost

204 estimates were then summed with the central-level costs to construct an estimate of the total economic

205 cost of the routine immunization program in Honduras for 2011.

Weighted average total facility-level system costs and weighted average facility-level system costs per dose were estimated for each type of health facility. System cost per dose was calculated at each level by dividing total immunization system costs at each level by total doses delivered in 2011 .

We estimated the total cost per fully immunized child (FIC) by summing both the vaccine cost and system cost required to complete the recommended national schedule for 1-year-old children, which

211 includes seven vaccines (14 doses in total). The estimate of vaccine and injection supply cost per FIC

212 included transaction costs, injection supplies, and wastage for relevant vaccines. System cost per FIC was 213 estimated for each vaccine by multiplying each recommended dose by the mean system cost per dose at 214 each level of the program. Additional results specific to the cost of vaccinating children up to 1 year old 215 were calculated to facilitate comparison between the study in Honduras and other EPIC country studies. 216 All statistical analysis was conducted in STATA12.

\section{Results}

\subsection{Total costs of routine immunization in Honduras}

The total cost to deliver the routine immunization program in Honduras for 2011 was US\$ 32.5 million. Vaccines and other supplies represented a large share of the costs, amounting to $25 \%$. However,

221 labor was the largest cost category, accounting for about half of the total cost (Table 3). Excluding

222 vaccine and injection supplies, about three quarters of the costs are incurred at the health facilities. Only $22314 \%$ and $9 \%$ of system costs occur at the regional and central offices, respectively. About $55 \%$ of all 
224 doses in the routine immunization program are delivered to children up to 1 year old. Analysis of program 225 costs for this population is described in Supplementary Appendix 2.

Labor costs are substantial at all levels, but the activities supported by these costs range widely

227 among the different program levels. Activities to support program management, including planning and

228 coordination, supervision, monitoring and evaluation, and research, are consistently a large share of total

229 labor across levels. In contrast, vaccine administration and social mobilization are more substantial at the

230 facility level. At the regional offices, labor costs are mostly associated with program management, cold

231 chain, and surveillance activities. Other labor costs that represent administrative and support activities,

232 such as for drivers and secretaries, carry a larger share of the costs at the central level.

Expenses to support the launch of a new vaccination in April 2011, against pneumococcal

234 disease, were also surveyed. Besides the cost of procuring the vaccine and needed supplies for the two

235 new vaccine programs (around US\$ 4.8 million, assuming GAVI prices of US\$ 7 per PCV dose and US\$

2362.50 per rotavirus dose), nationwide trainings and revision of vaccination manuals represented the only

237 other incremental costs identified for the 2011 study period. These costs totaled US\$142,300. The survey

238 of costs at the facility level did not reveal any incremental costs solely related to incorporating the new

239 vaccine.

241 introduction, Honduras had invested substantially in the cold chain infrastructure to ensure adequate

242 capacity for both rotavirus and PCV13. However, our study did not gather data on the cost of these

243 investments, which occurred prior to the 2011 study period. 
In 2011, more than 4 million doses of vaccine were delivered to protect children, adolescents, and

247 adults against 14 vaccine-preventable diseases. The mean system cost per dose to deliver the vaccines was

248 US\$ 5.97, of which 78\% occurred at the facility level. When accounting for the stratification by facility

249 type in the sample design, the facility-level system cost per dose delivered ranges from US\$ 1.58 (95\%

250 CI: US\$ 1.23-1.92) in hospitals to US\$ 7.68 (95\% CI: US\$ 4.16-11.21) in rural vaccination posts (Table

251 4). Regardless of facility type, facility-level system cost per dose was strongly (negatively) correlated

252 with volume of doses delivered (Table 5). Facilities delivering fewer than 500 doses per year have the

253 highest system cost per dose, at US\$25.55 per dose (95\% CI: US\$ 21.48-29.61). In contrast, the facilities

254 delivering 10,000 or more doses per year have the lowest system cost per dose, at US\$2.84 (95\% CI:

255 US\$2.03-3.66).

Focusing just on the cost of fully immunizing a child up to 1 year of age, we calculated that the

257 cost per FIC was US\$ 132.24. Of this cost, US\$ 48.67 (37\%) is for vaccine and injection supply and US\$

$25883.57(63 \%)$ is for system cost (Table 6). Since the total cost at regional and facility level accounts for the

259 sample design, and is extrapolated based on facility volume, type, and location, the cost per dose

260 represents a national average. Assuming the vaccine and delivery costs associated with the number of

261 doses for completing the recommended schedule for the new rotavirus and pneumococcal conjugate

262 vaccines, roughly $20 \%$ of the cost per FIC is associated with these vaccinations in 2011.

\section{Discussion}

Applying a rigorous methodology that included systematic data collection from a representative sample of health facilities and regional EPI offices, this study generated comprehensive, detailed, and precise estimates of resources actually used to deliver the national immunization program of Honduras. The study further benefited from the use of the COSTVAC tools developed by PAHO's ProVac Initiative 
270 and collaboration with the community of immunization-costing experts convened for the large

271 EPIcproject. The results have direct utility for policymakers in Honduras as they carry out strategic

272 planning for sustaining and improving the national immunization program. Additionally, the information

273 adds another dimension to assessments of program performance, and provides useful baseline information

274 for cost-effectiveness analysis and resource tracking over time.

In addition to being useful for policymakers and stakeholders in Honduras, the study also

276 generated three key insights that are beneficial more generally. First, the study contributes to a growing

277 literature showing that the "system costs" of high-quality immunization programs, particularly labor costs

278 for vaccine delivery, are significant, and should not simply be ignored. In many low- and middle-income

279 settings, including Honduras, health sectors are rapidly expanding both the coverage and scope of services

280 provided. However, the capacity of the health workforce is often a binding constraint on production.

281 Greater awareness of the current use of scarce human resources by different activities of the health sector

282 should aid efforts to align existing resources with health priorities and inform strategies to increase

283 resources.

Second, this study shows that system costs of immunization programs at the facility level range

widely, and that these costs are tightly correlated with the number of vaccine doses delivered. Similar

286 findings on the range in unit costs in different health service settings have been reported for Peru [16] and

287 for many other developing countries [17]. Additional studies are required to determine how much of the

288 observed range at the facility level is unavoidable, and how much represents an opportunity to improve

289 efficiency. However, this study suggests that achieving high coverage in sparsely populated areas will

290 require more resources per dose delivered than in urban areas. The less densely populated areas may have

291 somewhat lower wage levels, but they face fixed costs associated with ensuring that services are

292 geographically accessible to populations in these areas. With an increasing number of municipalities

293 registering DTP3 coverage rates below 80\% in Honduras [12], more resources may be needed to achieve

294 the goal of extending the benefits of immunization to all persons [18]. 
297 countries, these periodic campaigns mobilize a very large portion of workers in the health sector as well

298 as government workers in other sectors, plus numerous volunteers, for a period of two to three weeks at a

299 time. This massive community effort is responsible for delivering about $8 \%$ of the doses in Honduras, and

300 it is believed to be critical to achieving high population coverage and maintaining the public perception of

301 vaccination as an essential health intervention. Despite the important programmatic benefits that

302 campaign activities provide for completing childhood schedules and other targeted goals, these annual

303 drives are resource-intensive, and many of the resources consumed should be accounted for in the annual

304 budgeting process. While our study does not measure the opportunity cost of these campaigns in terms of

305 the health and other services foregone, it does value the time of all workers and volunteers (as well as

other inputs) consumed during the campaigns. These factors should be taken into consideration for future

307 planning efforts.

The study has several limitations. First, the study's design allows for standard statistical inference regarding the economic costs of vaccination in the eight regions surveyed. However, those regions were not selected at random. Therefore, our estimation of total national cost required the additional assumption that facilities in regions outside the sample frame are not systematically different from facilities of similar 312 size and type in the sampled regions. Because of this, uncertainty in our estimates is somewhat greater 313 than what is reflected in the reported confidence intervals. Secondly, labor cost at the facility level may 314 have been overestimated due to a reporting bias. Although the interview method and interviewer training 315 were designed to minimize this type of bias, we did not have a gold standard with which to validate the 316 method or measure the bias, if present. Additionally, in most cases, the person in charge of immunization 317 at the health facility reported her or his estimate of the fraction of the time each worker spent on 318 immunization activities. Although they were encouraged to, and often did, solicit information from other 319 health workers at the facility during the interview, it is reasonable to assume that the measure of health 
worker time allocated to immunization is imprecise. Ideally, future studies would validate the method by

321 comparing it to time-motion study or other more rigorous measurement methods. Third, the societal

322 perspective of this study did not measure household costs associated with time and travel costs for

323 vaccination. Fourth, our study was not able to allocate system costs to deliver specific vaccines, though it

324 is possible that certain vaccine types require more or fewer resources. Finally, the correlates of total

325 facility costs identified in this study are consistent with other published findings of facility-level cost

326 drivers. However, having further information on the relationship between coverage (or other program

327 performance measures) and total costs would help to refine recommendations on programmatic

328 efficiencies.

We expect much of the information collected will be useful in routine budgeting as well as in

330 strategic planning for new vaccine introduction, program quality improvement, and optimization of cost-

331 efficiency. However, care must be taken in those efforts. Our estimates are from one historical year, and

332 secular trends in unit costs and other contextual factors may necessitate updating or making adjustments

333 to the results of this study for use in the future. Additionally, some of the costs we report have no

334 corresponding financial transaction (e.g., volunteer time), and not all of the costs for immunization are

335 accounted for in the immunization program's budget. Indeed, facility-level labor is a major input that is

336 generally not included in the immunization budget. Finally, we did not estimate the marginal system cost

337 of increasing coverage or the marginal system cost of adding a new vaccine to the routine immunization

338 schedule. In the planning for marginal increases in scope or scale of the immunization program, we would

339 not recommend naively assuming that additional doses would have system costs equal to the average

340 system cost measured in this study. Nonetheless, in the context of planning for such increases, having the

341 information from this study is far better than having no systematic, comprehensive information about

342 resource use.

\section{5. CONCLUSIONS}


The study shows that even with the addition of new, more expensive vaccines to the routine

346 schedule, system costs account for the majority of the resources used in the delivery of Honduras'

347 national immunization program. System costs per dose delivered range widely among facilities, with the

348 costs being most strongly correlated with the number of doses delivered. The study contributes key

349 information to enable better mobilization and management of resources for immunization. Integrating the

350 type of costing data collected in this study with other program performance measures will enable more

351 accurate resource planning and identification of opportunities to improve cost efficiency.

\section{ACKNOWLEDGEMENTS}

353 We would like to extend our deepest thanks to the top notch data collector team that visited all 71 health

354 facilities and eight regional offices. The team of public health professionals that serve in management at

355 the national and regional levels in Honduras dedicated a substantial amount of time for interviews and

356 data gathering, and for this we are ever grateful. We also are indebted to the other EPIc country teams and

357 EPIc steering committee members for their constructive feedback and reviews of the data and technical

358 reports. And, finally, we would like to thank Logan Brenzel and Damian Walker for their support and

359 guidance in this process. This study was kindly financed by the Bill and Melinda Gates Foundation.

360 Contributors: CJ, IMB, CC, GF \& SR designed and implemented the study. LM, ID, IMB, GF \& CC

361 supported data collection. All authors contributed to data analysis and write up. All authors approved final

362 manuscript for publication. 


\section{REFERENCES}

369 [1] Andrus JK, Crouch AA, Fitzsimmons J, Vicari A, Tambini G. Immunization and the Millennium 370 Development Goals: progress and challenges in Latin America and the Caribbean. Health Aff

371 (Millwood). 2008 Mar-Apr;27(2):487-93. doi: 10.1377/hlthaff.27.2.487.

372 [2] Brenzal L, Claquin P. Immunization programs and their costs. Soc Sci Med. 1994 Aug;39(4):527-36.

373 [3] Lydon P, Levine R, Makinen M, Brenzel L, Mitchell V, Milstien JB, et al. Introducing new vaccines 374 in the poorest countries: What did we learn from the GAVI experience with financial sustainability?, 375 Vaccine. 2008 Dec 2;26(51):6706-16. doi: 10.1016/j.vaccine.2008.10.015.

376 [4] Lydon P, Gandhi G, Vandelaer J, Okwo-Bele JM. Health system cost of delivering routine vaccination 377 in low- and middle-income countries: what is needed over the next decade. Bull World Health Organ. 3782014 May 1;92(5):382-4. doi: 10.2471/BLT.13.130146. Epub 2014 Feb 7.

379 [5] Valdez W, Janusz C, Molina Berenice I, Mendoza L, Diaz IY, Resch S. Tracking financial flows for 380 immunization in Honduras. Vaccine. Forthcoming.

[6] Andrus JK, Toscano C, Lewis, Oliveira L, Ropero AM, Dávila M, Fitzsimmons JW. A model for 382 enhancing evidence-based capacity to make informed policy decisions on the introduction of new 383 vaccines in the Americas: PAHO's ProVac Initiative. Public Health Rep. 2007 Nov-Dec;122(6):811-6.

384 [7] Brenzal L, MORE, et al. Costs and financing of routine immunization: approach and findings of a 385 multi- country study (EPIC). Vaccine. Forthcoming.

386 [8] Valdez W, Janusz CB, and Resch S. Tracking financial flows for immunization in Honduras. Vaccine, 387 this issue. Doi: .

388 [9] Molina Berenice I, MORE, et al. Study of the cost-effectiveness of the introduction of the human 389 papillomavirus vaccine in Honduras. Vaccine. Forthcoming.

390 [10] WHO/UNICEF. Joint Reporting Form. Available at:

391 http://www.who.int/immunization_monitoring/data/en/.Accessed October 2013 .

392 [11] GAVI Alliance. GAVI awards countries and advocates for accelerating access to life-saving vaccines 393 [press release]. Available at: http://www.gavialliance.org/Library/News/Press-releases/2012/GAVI394 awards-countries-and-advocates-for-accelerating-access-to-life-saving-vaccines/. Accessed February 3952014. 
396 [12] Honduras Expanded Programme on Immunization, Secretary of Health, 2010. Multi-year plan of the 397 Expanded Program on Immunization in Honduras. [13] REF for line 143

398 [14] World Health Organization. WHO guide for standardization of economic evaluations of 399 immunization programmes. Geneva: WHO; 2008.

400 [15] Castañeda-Orjuela C, Romero M, Arce P, Resch S, Janusz CB, Toscano CM, et al. Using

401 standardized tools to improve immunization costing data for program planning: the cost of the Colombian 402 Expanded Program of Immunization. Vaccine. 2013 Jul 2;31 Suppl 3:C72-9. doi:

$403 \quad 10.1016 /$ j.vaccine.2013.05.038.

404 [16] Walker D, Mosqueira NR, Penny ME, Lanata CF, Clark AD, Sanderson CF, et al. Variation in the 405 costs of delivering routine immunization services in Peru. Bull World Health Organ. 2004 Sep;82(9):67640682.

407 [17] Bishai D, Mcquestion M, Chaudhry R, Wigton A. The cost of scaling up vaccination in the world's 408 poorest countries. Health Aff (Millwood). 2006 Mar-Apr;25(2):348-56.

409 [18] World Health Organization. Global vaccine action plan 2011-2020. Geneva: WHO: 2013.

410 [19] Pan American Health Organization. Immunization in the Americas 2013 Summary. Washington, 411 D.C.: PAHO; 2013.

412 [20] Pan American Health Organization, Revolving Fund. Vaccine prices for year 2014. Available at: 413 http://www.paho.org/hq/index.php?option=com_content\&view=article\&id=1864\&Itemid=4135.

414 Accessed February 2014. 
$1 \quad$ Table 1.

2 Recommended vaccination schedule in Honduras for children, adolescents, and risk groups, with relevant

3 costing data.

4

\begin{tabular}{lcccc}
\hline & $\begin{array}{c}\text { Doses } \\
\text { recommended } \\
\text { (number primary } \\
\text { Vaccine }\end{array}$ & $\begin{array}{c}\text { Target group } \\
\text { schedule } \\
\text { (month) }\end{array}$ & $\begin{array}{c}\text { Price per } \\
\text { dose } \\
\text { (US\$, 2011) }\end{array}$ & $\begin{array}{c}\text { Wastage } \\
(\%)\end{array}$ \\
\hline BCG & 1 & 0 & $\$ 0.10$ & $68 \%$ \\
Hepatitis B (HepB) & 1 & 0 & $\$ 0.23$ & $0 \%$ \\
Oral polio (OPV) & $3+1$ & $2,4,6,18$ & $\$ 0.21$ & $18 \%$ \\
Pentavalent (DTP+HepB+Hib) & 3 & $2,4,6$ & $\$ 3.19$ & $1 \%$ \\
Pneumococcal conjugate, 13-valent & $3+1$ & $2,4,6,18$ & $\$ 7.00^{\mathrm{a}}$ & $7 \%$ \\
(PCV13) & 2 & 2,4 & $\$ 2.50^{\mathrm{a}}$ & $2 \%$ \\
Rotavirus & 2 & 18,48 & $\$ 0.18$ & $19 \%$ \\
Diphtheria-tetanus-pertussis (DTP) & 1 & 18 & $\$ 1.60$ & $3 \%$ \\
Measles-mumps-rubella (MMR) & 1 & Risk groups & $\$ 0.08$ & $24 \%$ \\
Tetanus-diphtheria (Td) & 1 & Risk groups & $\$ 0.67$ & $40 \%$ \\
Yellow fever (YF) & 1 & Risk groups & $\$ 3.60$ & $21 \%$ \\
Influenza & Risk groups & $\$ 5.50$ & - \\
Inactivated polio (IPV) & NR & & & \\
\hline
\end{tabular}

5

$6 \quad{ }^{a}$ GAVI prices; all other prices are referenced from PAHO Revolving Fund.

$7 \quad$ bot reported 
10

11

12

13

\section{Table 2}

Characteristics of sampled and non-sampled administrative offices and health facilities administering the routine immunization program in Honduras.

\begin{tabular}{|c|c|c|c|c|}
\hline Characteristic & \multicolumn{2}{|c|}{ Sample } & Frame & Nationwide \\
\hline Number of central office & \multicolumn{2}{|l|}{1} & 1 & 1 \\
\hline Number of regional offices & \multicolumn{2}{|l|}{8} & 8 & 20 \\
\hline by type: non-metropolitan & \multicolumn{2}{|l|}{6} & 6 & 18 \\
\hline by type: metropolitan & \multicolumn{2}{|l|}{2} & 2 & 2 \\
\hline Number of health facilities & \multicolumn{2}{|l|}{71} & 784 & 1535 \\
\hline by type: CESAMO & \multicolumn{2}{|l|}{37} & 211 & 412 \\
\hline by type: CESAR & \multicolumn{2}{|l|}{31} & 526 & 1020 \\
\hline by type: hospital & \multicolumn{2}{|l|}{3} & 14 & 30 \\
\hline By type: other & \multicolumn{2}{|l|}{0} & 31 & 73 \\
\hline Total population under 1 year old & \multicolumn{2}{|c|}{63,632} & 102,709 & 177,733 \\
\hline \multirow{2}{*}{ Total doses applied } & \multicolumn{2}{|c|}{541,862} & 2450891 & $4,104,310$ \\
\hline & Metro & $\begin{array}{l}\text { Non- } \\
\text { metro }\end{array}$ & & \\
\hline mean doses applied by type: CESAMO & 15,104 & 4792 & 6822 & 5270 \\
\hline mean doses applied by type: CESAR & 1926 & 1089 & 1160 & 1182 \\
\hline mean doses applied by time: hospital & 20,133 & 20,646 & 24,390 & 16,671 \\
\hline Fraction of total doses applied during PIRI & 0.098 & & 0.0972 & 0.0927 \\
\hline $\begin{array}{l}\text { Fraction of total doses applied to children under } 1 \\
\text { year old }\end{array}$ & 0.614 & & 0.6416 & 0.6498 \\
\hline
\end{tabular}

14

$15 *$ PIRI = periodic intensification of routine immunization. 
Table 3

Total cost of the routine immunization program in Honduras (2011 US dollars, in thousands).

21

CAPITAL COSTS

\begin{tabular}{lrrcr}
\hline Category & Facility & Regional & Central & All Levels \\
\hline $\begin{array}{l}\text { Vaccine } \\
\text { and } \\
\text { supplies }\end{array}$ & $\$ 0$ & $\$ 0$ & $\$ 0$ & $\$ 0$ \\
\hline Labor & $\$ 0$ & $\$ 0$ & $\$ 0$ & $\$ 0$ \\
\hline Volunteers & $\$ 0$ & $\$ 0$ & $\$ 0$ & $\$ 0$ \\
\hline Cold chain & $\$ 625$ & $\$ 176$ & $\$ 12$ & $\$ 813$ \\
\hline Vehicles & $\$ 53$ & $\$ 44$ & $\$ 65$ & $\$ 162$ \\
\hline Buildings & $\$ 613$ & $\$ 104$ & $\$ 17$ & $\$ 734$ \\
\hline Other & $\$ 28$ & $\$ 10$ & $\$ 103$ & $\$ 141$ \\
\hline TOTAL & $\$ 1319$ & $\$ 334$ & $\$ 197$ & $\$ 1850$ \\
\hline
\end{tabular}

RECURRENT COSTS

\begin{tabular}{lrrrr}
\hline Category & Facility & Regional & Central & All Levels \\
\hline $\begin{array}{l}\text { Vaccine } \\
\text { and } \\
\text { supplies }\end{array}$ & $\$ 0$ & $\$ 0$ & $\$ 7990$ & $\$ 7990$ \\
\hline Labor & $\$ 15,404$ & $\$ 1800$ & $\$ 449$ & $\$ 17,653$ \\
\hline Volunteers & $\$ 713$ & $\$ 0$ & $\$ 0$ & $\$ 713$ \\
\hline Cold chain & $\$ 357$ & $\$ 70$ & $\$ 30$ & $\$ 457$ \\
\hline Vehicles & $\$ 60$ & $\$ 71$ & $\$ 21$ & $\$ 152$ \\
\hline Buildings & $\$ 220$ & $\$ 0$ & $\$ 6$ & $\$ 226$ \\
\hline Other & $\$ 1021$ & $\$ 1046$ & $\$ 1381$ & $\$ 3448$ \\
\hline TOTAL & $\$ \mathbf{1 7 , 7 7 5}$ & $\mathbf{\$ 2 9 8 7}$ & $\mathbf{\$ 9 8 7 7}$ & $\mathbf{\$ 3 0 , 6 3 9}$ \\
\hline
\end{tabular}

TOTAL COSTS

\begin{tabular}{lrrrrr}
\hline Category & Facility & Regional & Central & TOTAL & \\
\hline $\begin{array}{l}\text { Vaccine } \\
\text { and }\end{array}$ & $\$ 0$ & $\$ 0$ & $\$ 7990$ & $\$ 7990(25 \%)$ \\
supplies $^{\text {a }}$ & & & & &
\end{tabular}




\begin{tabular}{lrrrr}
\hline Labor & $\$ 15,404$ & $\$ 1800$ & $\$ 449$ & $\$ 17,653(54 \%)$ \\
\hline Volunteers & $\$ 713$ & $\$ 0$ & $\$ 0$ & $\$ 713(2 \%)$ \\
\hline Cold chain & $\$ 982$ & $\$ 246$ & $\$ 42$ & $\$ 1270(4 \%)$ \\
\hline Vehicles & $\$ 113$ & $\$ 115$ & $\$ 86$ & $\$ 314(1 \%)$ \\
\hline Buildings & $\$ 833$ & $\$ 104$ & $\$ 23$ & $\$ 960(3 \%)$ \\
\hline Other & $\$ 1049$ & $\$ 1056$ & $\$ 1484$ & $\$ 3589(11 \%)$ \\
\hline TOTAL & $\mathbf{\$ 1 9 , 0 9 4}$ & $\mathbf{\$ 3 3 2 1}$ & $\mathbf{\$ 1 0 , 0 7 4}$ & $\mathbf{\$ 3 2 , 4 8 6 ( 1 0 0 \% )}$
\end{tabular}

22

$23{ }^{a}$ Note: Total vaccine costs reflect the following assumptions: (1) PCV13 and rotavirus price per dose consider

24 GAVI-manufacturer price agreements of US\$ 7.00 per dose and US\$ 2.50 per dose, respectively, and (2) vaccine 25 and supply costs for PPV23 (2011 donation) were excluded.

26 
$29 \quad$ Table 4

30 Weighted average delivery cost per dose, by facility type (2011 US dollars).

31

\begin{tabular}{lrrlll}
\hline Facility type & Obs. & Mean & SE & $95 \%$ CI LB & 95 CI\% UB \\
\hline CESAMO & 37 & $\$ 4.56$ & $\$ 0.60$ & $\$ 3.34$ & $\$ 5.77$ \\
CESAR & 31 & $\$ 7.68$ & $\$ 1.75$ & $\$ 4.16$ & $\$ 11.21$ \\
HOSPITAL & 3 & $\$ 1.58$ & $\$ 0.17$ & $\$ 1.23$ & $\$ 1.92$ \\
\hline
\end{tabular}

32

33 
35 Table 5

36 Weighted average delivery cost per dose, by facility output category (2011 US dollars).

37

\begin{tabular}{lccccc}
\hline $\begin{array}{l}\text { Facility size } \\
(\text { no. of doses) }\end{array}$ & Obs. & Mean & SE & $95 \%$ CI LB & $95 \%$ CI UB \\
\hline $\begin{array}{l}\text { Huge } \\
(>=10,000)\end{array}$ & 16 & $\$ 2.84$ & $\$ 0.40$ & $\$ 2.03$ & $\$ 3.66$ \\
\hline $\begin{array}{l}\text { Large } \\
(5000-9999)\end{array}$ & 4 & $\$ 4.63$ & $\$ 1.67$ & $\$ 1.28$ & $\$ 7.97$ \\
\hline $\begin{array}{l}\text { Medium } \\
(1500-4999)\end{array}$ & 20 & $\$ 5.05$ & $\$ 0.85$ & $\$ 3.34$ & $\$ 6.75$ \\
\hline $\begin{array}{l}\text { Small } \\
(500-1499)\end{array}$ & 27 & $\$ 9.28$ & $\$ 0.83$ & $\$ 7.61$ & $\$ 10.96$ \\
\hline $\begin{array}{l}\text { Tiny } \\
(<500)\end{array}$ & 4 & $\$ 25.55$ & $\$ 2.02$ & $\$ 21.48$ & $\$ 29.61$ \\
\hline
\end{tabular}

38

39 
42 Table 6

43 Cost per fully immunized child (FIC) at age of 1 year in Honduras (2011 US dollars).

44

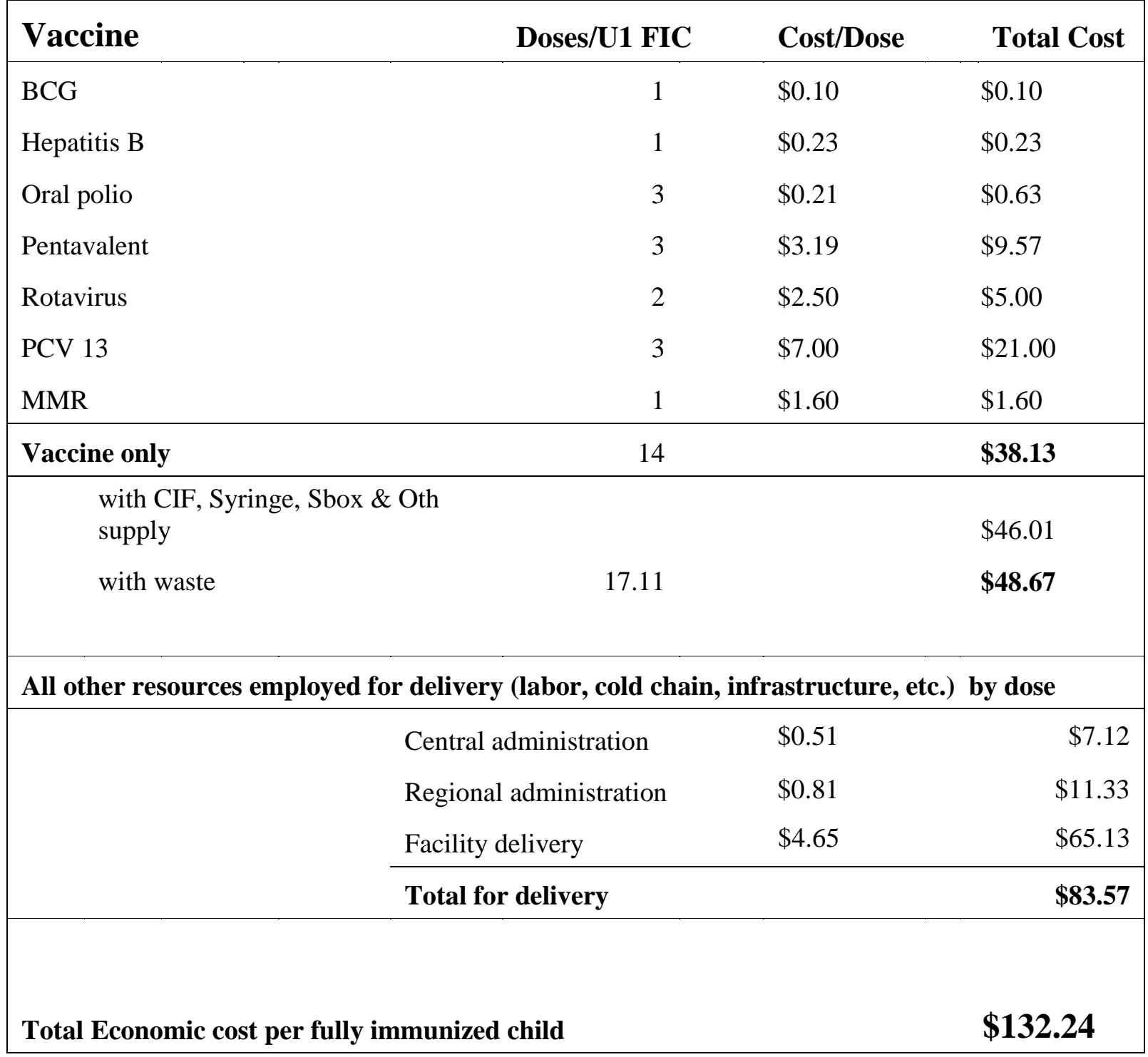

45

46 
Box 1

Definitions of EPI planning and budgeting components in PAHO Region

\begin{tabular}{|c|c|}
\hline EPI Component & Cost definition \\
\hline $\begin{array}{l}\text { Political priority, advocacy and legal } \\
\text { basis }\end{array}$ & $\begin{array}{l}\text { Time and resources dedicated to advocacy and } \\
\text { policy, including developing legal frameworks for } \\
\text { immunization. }\end{array}$ \\
\hline Planning and coordination & $\begin{array}{l}\text { Time and resources dedicated to managing, } \\
\text { planning, and budgeting and coordinating at all } \\
\text { levels of the program. }\end{array}$ \\
\hline Vaccines and supplies & Includes all vaccines and safe injection supplies. \\
\hline Cold chain & $\begin{array}{l}\text { Time and resources dedicated to installing, } \\
\text { maintaining and using the cold chain, which } \\
\text { encompasses vaccine storage and distribution. }\end{array}$ \\
\hline Training & $\begin{array}{l}\text { Time and resources developing, administering } \\
\text { and/or participating in training and continuous } \\
\text { learning opportunities. }\end{array}$ \\
\hline Social mobilization & $\begin{array}{l}\text { Time and resources dedicated to community level } \\
\text { mobilization to raise awareness about vaccination, } \\
\text { including television spots, information and } \\
\text { education campaigns, and importantly resources } \\
\text { dedicated to support the Jornadas Nacionales de } \\
\text { Vacunación. }\end{array}$ \\
\hline Other operating costs & $\begin{array}{l}\text { Time and resources dedicated to other recurrent } \\
\text { and capital costs of the immunization program, for } \\
\text { example printing and office furniture. }\end{array}$ \\
\hline Monitoring and supervision & $\begin{array}{l}\text { Time and resources dedicated to local level staff to } \\
\text { perform supervision visits and meetings in order to } \\
\text { monitor coverage and other performance } \\
\text { indicators. }\end{array}$ \\
\hline $\begin{array}{l}\text { Surveillance, vaccine safety and } \\
\text { laboratories }\end{array}$ & $\begin{array}{l}\text { Time and resources dedicated to epidemiological } \\
\text { investigation of Adverse Events Following } \\
\text { Immunization (AEFI) and VPD outbreaks. }\end{array}$ \\
\hline Information systems & $\begin{array}{l}\text { Time and resources dedicated to record keeping } \\
\text { and reporting data between programmatic levels. }\end{array}$ \\
\hline Research & $\begin{array}{l}\text { Time and resources dedicated to operational } \\
\text { research. }\end{array}$ \\
\hline Evaluation & $\begin{array}{l}\text { Time and resources dedicated to evaluating } \\
\text { program performance at sub-national and national } \\
\text { level. }\end{array}$ \\
\hline
\end{tabular}

